\title{
COMUNICACIÓN
}

\section{DESARROLLO DE UN MÉTODO DE ELECTROINMUNOTRANSFERENCIA PARA LA DETECCIÓN DE ANTICUERPOS ANTI Sarcocystis aucheniae EN ALPACAS}

\author{
Rosa Sam T. ${ }^{1}$, Armando González Z. ${ }^{1}$, Teresa López U. ${ }^{1}$ y Manuela \\ Verástegui P.2
}

\section{Wistrat}

A western blot assay to detect antibodies against Sarcocystis aucheniae (SA) from alpacas was developed for in vivo diagnosis of sarcocystiosis in domestic camelids. The antigen consists of a soluble extract obtained from SA macrocysts (MSA) of naturally infected alpacas. A SDS-PAGE (15\%) electrophoretic analysis revealed fifteen peptides at $25-127 \mathrm{kDa}$. Western blot assay of sera from MSA immunized rabbits detected three peptides at $58-50 \mathrm{KDa}$, while the sera from SA diagnosed alpacas reacted against four protein bands. Sera from neonate alpacas and from non-SA infected alpacas did not display reactivity to the MSA peptides. Specific immune reactivity of the alpaca antibodies against SA with four MSA peptides by a western blot assay has been documented.

Key words: Macrocysts, antigen, western blot.

Palabras clave: Macrocystis, antígeno, electroinmunotransferencia.

Sarcocystis aucheniae es un protozoo de ciclo indirecto responsable de la sarcocistiosis en camélidos sudamericanos. En el ciclo biológico del protozoo intervienen carnívoros como hospedadores definitivos en los que se desarrolla la fase sexual del parásito y herbívoros como los camélidos, como hospedadores intermediarios donde evoluciona en su fase esquizogónica en el endotelio y posteriormente se enquista en la musculatura cardiaca y esquelética (Leguía y et al., 1989). Estudios previos indican que proteínas de lisados de macroquistes de Sarcocystis aucheniae (MSA) reaccionan con inmunoglobulinas Gespecíficas de conejo en

1 Laboratorio de Microbiología - FMV UNMMS.E.Mail:d170031@unmsm.edu.pe 2 Práctica privada la prueba indirecta de ELISA (Ramírez y et al., 1994), anticuerpos de caballos anti Sarcocystis neurona fueron medidos por un método de electro-inmunotransferencia blot (Blythe et al., 1997; Saville, et. al., 1977; Miller, 1999). Las proteínas constituyentes de MSA incluyen algunas con propiedades tóxicas, que podrían ser compatibles con las contenidas en la endotoxina denominada sarcocistina referida por Senaud (1968) las mismas que ocasionan la muerte de conejos debido a la producción de alteraciones histopatológicas agudas en diferentes órganos vitales (Sam, et al., 1998). La prevalencia elevada de sarcocistiosis en camélidos domésticos (98-100\%) reportada por Guerrero y et al. (1967) y las pérdidas anuales por decomisos de carcasas de alpacas y estimada en \$ 296,822 (Guerrero y Leguia, 1987), justifica la disponibilidad determinación 
de un método de diagnóstico in vivo de esta enfermedad. El objetivo de la investigación fue estandarizar un método de revelado de la electroinmunotransferencia (EITB) para la identificación de inmunoglobulinas $\mathrm{G}$ anti Sarcocystis aucheniae (SA) para su aplicación en el diagnóstico de la sarcocistiosis en alpacas y llamas.

\section{Preparación del antígeno de Sarcocystis aucheniae}

Para la preparación del antígeno se siguió el protocolo de Sam y et al. (1998) con ligeras variantes. Los macroquistes se colectaron de músculos estriados de alpacas infectadas naturalmente y se suspendieron inmediatamente en solución salina de fosfatos (SSF) $0.15 \mathrm{M} \mathrm{pH} 7.2$ suplementada con el inhibidor de proteasas PMSF (fenilmetil sulfonil fluoruro $0.25 \mathrm{M}$ ). Luego de 30 minutos los quistes se lavaron 3 veces por decantación con SSF, se homogeneizaron y se lisaron por ultrasonicación (Fisher-300) con una amplitud de 60 ciclos $(60,000 \mathrm{~Hz})$ durante 9 minutos en intervalos de 3 minutos. El lisado se centrifugó a 12,000 x g durante 30 minutos. El contenido de proteína total del lisado se determinó mediante el método de Bradford (1976).

\section{Obtención de suero hiperinmune anti- Sarcosytis aucheniae}

Las inmunoglobulinas específicas anti MSA fueron producidas en conejos siguiendo la metodología descrita por Sam (1988). Dos conejos de tres kilos de peso vivo fueron inmunizados aplicando por cuatro veces a intervalos de 15 días vía intradérmica en 20 puntos, cada vez, dosis de $0.25 \mathrm{mg}$ de proteína de lisado de MSA/ kilo de peso, inactivado con formol $(0.4 \%)$ y emulsificado con adyuvante de Freund incompleto. Muestras de sangre fueron colectadas antes de la primera inoculación y después de la última inoculación para determinar los niveles de anticuerpos contra MSA.

\section{Muestras para la prueba de EITB}

Para el desarrollo de la prueba de EITB se utilizaron sueros procedentes de alpacas positivas a la infección confirmada por necropsia y de alpacas negativas a la infección confirmada por necropsia y procedentes de zonas libres de sarcocistiosis. Asimismo se utilizaron sueros de alpacas neonatas carentes de calostro.

\section{Desarrollo de la electroforesis y de la prueba de EITB}

La movilidad electroforética de las proteínas contenidas en la suspensión de MSA se determinó en geles de electroforesis de poliacrilamida con dodecil sulfato de sodio (SDS-PAGE) de concentración al $4 \%$ y de separación al $15 \%$ según la técnica descrita por Laemmli (1970). El lisado crudo (64 $\mu \mathrm{g} /$ $10 \mu 1)$ diluído en tampón de muestra $5 \mathrm{X}$ se aplicó al gel en una mini-cámara electroforética (Mini Protean II Cell Bio Rad) y se electroforizó a 200 voltios durante 36 minutos. El marcador de peso molecular compuesto por proteínas de referencia de bajo peso molecular (14.4 a $200 \mathrm{kDa}$ ) se incorporó en la electroforesis a fin de estimar la movilidad relativa de las proteínas sujetas al análisis.

La prueba de EITB se desarrolló siguiendo la metodología descrita por Tsang (1983). Los péptidos del lisado de MSA resultantes de la migración electroforética en SDS-PAGE fueron transferidos a una membrana de nitrocelulosa (Gene Screen, NEN Research Products, Boston MA) en una minicámara de transferencia (Bio Rad) a 100 voltios durante 60 minutos. Posteriormente la membrana se bloqueó con una solución tampón de fosfatos (PBS)- Tween 20 (T20) $0.05 \%$ y leche descremada (Difco) $5 \%$ durante 1 hora a temperatura ambiente $\left(20^{\circ} \mathrm{C}\right)$ y en agitación constante. Luego se procedió a un primer lavado con PBS-T20 calentado a $55^{\circ} \mathrm{C}$, dos lavados con PBS-T20 a temperatura ambiente y dos con PBS. 
La membrana de nitrocelulosa se cortó en tiras de $4 \mathrm{~mm}$ de ancho y estas se incubaron durante 3 horas a $37^{\circ} \mathrm{C}$ con los sueros diluídos en tampón de bloqueo PBS-T20 $0.05 \%$-leche descremada $5 \%$. Los sueros de conejo se diluyeron en tampón de bloqueo $1: 200$ y $1: 500$ y los sueros de alpaca $1: 25$ y 1:50. La reacción fue detectada en los sueros de conejo con Ig $\mathrm{G}$ anti Ig $\mathrm{G}$ de conejo conjugada con enzima peroxidasa (KPL) y en los sueros de alpaca con proteína A conjugada con peroxidasa (KPL) diluída 1:200 mediante la incubación durante 1 hora a $37^{\circ} \mathrm{C}$. La reacción inmunológica en ambos casos fue revelada mediante la incubación con una solución de diaminobencidina DAB $(10 \mathrm{mg} /$ $\mathrm{ml}$ ), $40 \mathrm{ml}$ de acetato de amonio $\mathrm{pH} 5.0$ y 40 $\mathrm{ml}$ de peróxido de hidrógeno durante $10 \mathrm{mi}$ nutos a temperatura ambiente. Las tiras se lavaron con agua destilada para detener la reacción.

El contenido de proteína total del lisado fue de $6.4 \mathrm{mg} / \mathrm{ml}$. Mediante el análisis electroforético en geles SDS-PAGE al 15\% se determinaron 15 bandas protéicas de movilidad electroforética entre 25 a $127 \mathrm{kDa}$. El suero de los conejos inmunizados reaccionó con varios péptidos del extracto soluble de MSA. Se observó una fuerte reacción con 3 bandas de movilidad relativa entre 58 a 50 $\mathrm{kDa}$. Los sueros colectados antes de la inoculación de los conejos no reaccionaron con ninguna banda del extracto soluble de MSA, resultados semejantes a lo encontrado por Mencke, et al. (1991) con policlonales anti Sarcocystis muris.

Los resultados de la detección de anticuerpos presentes en los sueros de las alpacas positivas a SA por medio de la proteína A conjugada con peroxidasa concuerdan con los trabajos de detección de anticuerpos mediante la proteína $\mathrm{A}$ en alpaca realizados por López y González (1992). Diversos trabajos epidemiológicos demuestran la efectividad de la prueba de EITB para el diagnóstico de Sarcocystis neurona en equinos (Granstrom et al., 1993; Blythe et al., 1997; Saville et al., 1997; Bentz et al.,
1997; Miller et al., 1999). Los sueros de las alpacas positivas a SA tuvieron una reacción fuerte con bandas comprendidas entre 58 a $50 \mathrm{kDa}$ y la ausencia de reacción de los sueros de los animales neonatos y de alpacas adultas negativas provenientes de zonas libres con ninguno de los péptidos del extracto soluble, indica una reacción inmunológica específica entre los 4 péptidos de MSA y anticuerpos de alpacas afectadas naturalmente con sarcocistiosis.

\section{Viteratura Cindh}

1. Bentz, B.G., D.E. Granstrom y S. Stamper. 1997. Seroprevalence of antibodies to Sarcocystis neurona in horses residing in a county of southeastern Pennsylvania. J Am Vet Med Assoc, 210:517-518.

2. Blythe, L.L., D.E. Granstrom, D.E. Hansen, L.L. Walker, J. Bartlett y S. Stamper. 1997. Seroprevalence of antibodies to Sarcocystis neurona in horses residing in Oregon. J Am Vet Med Assoc, 210:525-527.

3. Bradford, M.M. 1976. A Rapid and Sensitive Method for the Quantitation of Microgram Quantities of Protein Utilizing the Principle of Protein-Dye Binding. Anal Biochem, 72:248-254.

4. Granstrom, D.E., J.P. Dubey, S.W. Davis, R. Fayer, J.C. Fox, K.B. Poonacha, R.C. Giles y P.F. Comer. 1993. Equine protozoal myeloencephalitis: antigen analysis of cultured Sarcocystis neurona merozoites. J Vet Diagn Invest, 5:88-90.

5. Guerrero, C, J. Hernandez y J. Alva. 1967. Sarcocystis en alpacas, Rev. Fac. Med. Vet. UNMSM . 21:69-72

6. Guerrero C.A. y G. Leguía. 1987. Enfermedades parasitarias de las alpacas. Rev. de Camélidos Sudamericanos. Enfermedades Infecciosas y Parasitarias de las Alpacas. UNMSM-IVITA-CICCS 9:37-42.

7. Laemmli, U.K. 1970. Cleavage of estructural proteins during the assembly 
of the head of bacteriophage T4. Nature, 227:680-685.

8. Leguia, G., C. Guerrero, R. Sam y A. Chávez. 1989. Infección Experimental de perros y gatos con micro y macroquistes de Sarcocystis de alpacas (Lama pacos). Rev. De Cienc. Vet. Vol.5 No.3. pp.10-13. Lima Perú..

9. López Urbina, M.T. y A.E. González. 1992. Estandarización del Sistema Inmunoenzimático de detección de Anticuerpos de alpaca (Lama pacos) Utilizando Proteína A Conjugada con Peroxidasa. Theorema, UNMSM, Lima, 2:44-45.

10. Mencke, N., P.O. O'Donoghue, R. Lumb, P. Smith, A.M, Tenter, P. Thummel y M. Rommel. 1991. Antigenic characterisation of monoclonal antibodies against Sarcocystis muris by Western blotting and immuno-electron microscopy. Parasitol Res, 77:217-223.

11. Miller, M.M., C.R. Sweeney, G.E. Russell, R.M. Sheetz y J.K. Morrow. 1999. Effects of blood contamination of cerebrospinal fluid on western blot analysis for detection of antibodies against Sarcocystis neurona and on albumin quotient and immunoglobulin $G$ index in horses. J Am Vet Med Assoc, 215:67-71.

12. Ramírez, A., R.E. Sam y D. Pezo. 1994. Método de ELISA en la detección de anticuerpos contra Sarcocystis aucheniae. Theorema, UNMSM Lima, 3:44-45.

13. Sam, R.E. 1988. Sarcocystis aucheniae: Caracterización parcial de componentes antigénicos y Patología clínica experimental en alpacas. Tesis para optar el Grado Académico de Doctor en Ciencias Biológicas. p.118. Univ. Nac. Mayor de San Marcos, LimaPerú.

14. Sam, R.E., I. Mansilla, C. Morales y A. Ramírez. 1998. Efecto tóxico de Macroquistes d Sarcocystis aucheniae en ratones, cobayos y conejos. Rev. Inv. Pec. IVITA (Peru), 9(2):11-18

15. Saville, W.J., S.M. Reed, D.E. Granstrom, K.W. Hinchcliff, C.W. Kohn, T.E. Wittum y S. Stamper. 1997. Seroprevalence of antibodies to Sarcocystis neurona in horses residing in Ohio. J Am Vet Med Assoc, 210:519524.

16. Seanud J., $R$. Vendrely y P. Tronche. 1968. Sur le nature de la substance toxique des Kistes de Sarcosporidies du mounton (Toxoplasmea) active sur le lapin. C.R. Acad. Sc. Paris 266:11371138

17. Tsang V. C. W., J.M. Peralta y A.R. Simons. 1983. Enzyme-linked immunoelectrotransfer blot techniques (EITB) for studying the specificities of antigens and antibodies separated by gel electrophoresis. Methods Enzymol. 92:377-391. 